\title{
Evaluation of p53 and Ki67 Expression Profiles in Basal Cell Carcinomas in a Usual and an Unusual Location
}

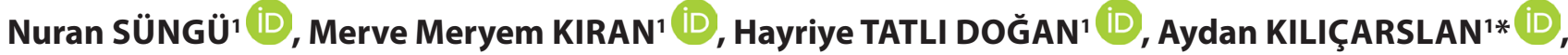 \\ Emre KARAKÖK' ${ }^{1}$ Mesut AKYOL²
}

Department of 'Pathology, ${ }^{2}$ Biostatistics, Ankara YIldırım Beyazit University, Ankara Ataturk Research and Training Hospital, ANKARA, TURKEY

\begin{abstract}
Objective: Owing to their importance in cell proliferation in cutaneous malignancies, we aimed to immunohistochemically compare the expression profiles of p53 and Ki67 in basal cell carcinoma (BCC) cases in both a usual and an unusual locations in this study.

Material and Method: In this study we included 12 in an unusual location of BCC cases and 21 BCC cases in a usual location. Immunohistochemical expression of p53 and Ki67 antibodies were studied in 33 paraffin-embedded tissue specimens of basal cell carcinoma. We compared the p53 and Ki67 staining scores with clinicopathologic features.

Results: The tumor size was found to be greater in BCC cases in an unusual location than those in a usual location. The relationship between age and tumor size was also evaluated in both groups and it was found that tumor size increased with age. A comparative study between the two groups showed no difference p53 and Ki67 expression percentages. There was a linear correlation between the Ki67 and p53 marker staining rates $(\rho=0.420 ; p=0.015)$. In the samples taken from cases in a usual region, there was a linear and moderate relationship between the markers $(\rho=0.513 ; p=0.017)$. Median tumor diameter results were similar to the marker staining score $(p>0.05)$.

Conclusion: This is the first study comparing the expression profiles of p53 and Ki67 of BCC cases in an unusual and a usual location. No significant difference was found concerning Ki67 and p53 expression levels between the two groups.
\end{abstract}

Key Words: Basal cell carcinoma, p53, Ki67, Location

\section{INTRODUCTION}

Basal cell carcinomas (BCC) are the most frequent type of non-melanoma malignancies and their frequency increases with aging $(1,2)$. BCC cases have a slow clinical course and are seen with local recurrences (2). However, regional lymph node, lung and bone metastases have only been reported in rare cases. The main etiological reasons are exposure to sunlight and genetic factors. Additionally, several etiological factors such as immunosuppression, male gender, scar tissue, arsenic intake and nevus syndrome may be responsible for the etiology (3).

BCC is characterised by basaloid cells showing peripheral palisading and also peritumoral spaces associated with a surrounding loose fibromucinous stroma (Figure 1) (4).

Although BCC is seen quite often, it occurs rarely in some parts of the body. Those in an unusual location constitute $1.2 \%$ of all cases (4).

$\mathrm{P} 53$ gene mutation is also responsible for BCC progression, as in several other tumor types. P53 is a tumor suppressor gene which is defective in malignancies and p53 mutation has been reported in more than $50 \%$ of human malignancies

(Turk Patoloji Derg 2018, 34:165-170)

Received : 06.10.2017 Accepted : 19.02.2018
(5-7). The p53 gene mutation is important in BCC cases that have defined UV light exposure. Various expressions have been demonstrated by p53 immunohistochemical testing of BCC cases. Additionally, the relation between p53 expression and aggressive progression has been shown (7).

DNA damage is caused by endocellular factors such as oxygen radicals or extracellular factors such as UV light. Under normal conditions, the p53 tumor suppressor gene arrests the cell cycle or induces apoptosis after DNA damage. In fact, if there is a mutation in the $\mathrm{p} 53$ gene, these functions are lost. Then the apoptosis capacity is decreased and a tumor can develop (5). Ki67 is a high molecular weight non-histone protein that has a controlling effect at several points in the cell cycle. It is usually associated with proliferation and particularly with cell proliferation. Increased Ki67 expression is seen in several tumor types and in skin damaged due to exposure to sunlight (7).

Owing to their importance in cell proliferation in cutaneous malignancies, we aimed in this study to immunohistochemically compare the expression profiles of p53 and Ki67 in BCC cases located in both common and rare areas.

Correspondence: Nuran SÜNGÜ

Department of Pathology, Ankara Yıldırım Beyazit University,

Ankara Ataturk Research and Training Hospital, ANKARA, TURKEY

E-mail: nuransungu@gmail.com Phone:+90 3122912525

*This authors contributed equally to this work. 


\section{MATERIAL and METHODS}

We included 1208 patients with a BCC diagnosis who were consulted in our hospital between 2006 and 2017 in this study. Their results were then analysed retrospectively. BCC cases involving the head, neck, body, scalp and extremities were accepted as common areas. BCC cases in the vulva, inguinal, axilla, nipple-areola complex, umbilicus, thigh, and the periungual, scrotal and anal regions were accepted as rare areas (8). H\&E sections of 12 BCC cases in an unusual location were re-examined. During the same time period, $21 \mathrm{BCC}$ cases in a usual location were selected and the nodular type was the most frequent histopathological variant.

Anti-p53(p53-DO7-L-CE) and Ki67(MIB-1) antibodies with a 1/100 dilution rate were performed in all cases. Immunohistochemical staining was performed by preparing 3-4 $\mu$ thickness surface sections from formalin-fixed paraffin blocks of the cases to poly-l-lysine coated slides using a Leica Bond-Max automatic immunohistochemical staining machine. Subsequently immunohistochemical stained slides were examined in two groups. The expression levels of p53 and Ki67 antibodies were evaluated in the peak staining density area by a percentage value (\%). Additionally, scoring was also carried out and a 5\% cut-off rate for $\mathrm{p} 53$ and Ki-67 antibody were performed. Ki-67 and p53 positive cells were scored as follows: $0-5 \%$ positive cells=negative, $6-25 \%=1+, 26-50 \%=2+, 51-75 \%: 3+,>75 \%=4+$. The scores were reclassified as 'low' for score 1-2+ and 'high' for score $3-4+(9)$.

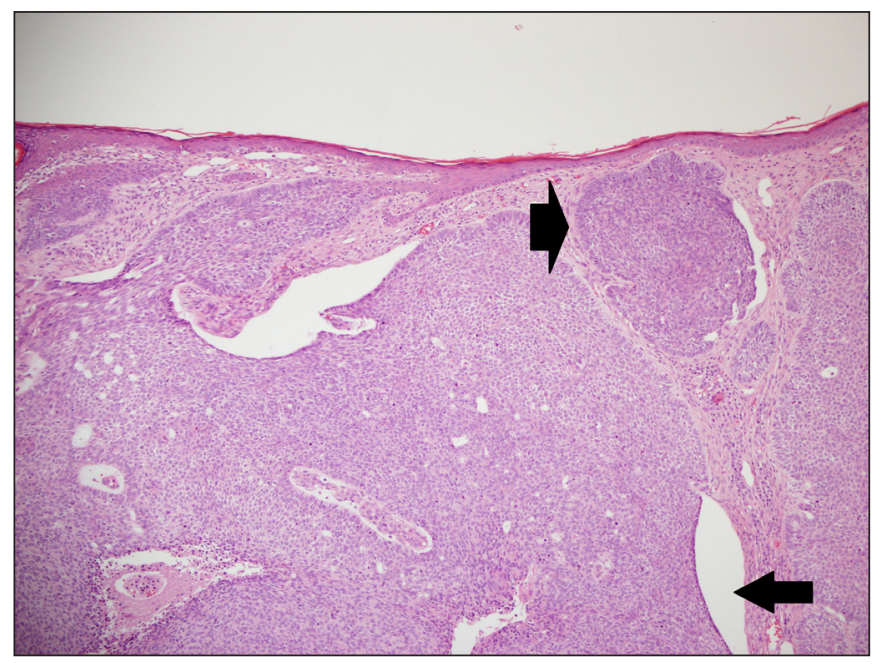

Figure 1: The nodular type of BCC is characterised by basaloid cells showing peripheral palisading (short arrow) and also peritumoral cleavages associated with a surrounding loose fibromucinous stroma (long arrow) (H\&E; x100).
In the representation of descriptive statistics, median (InterQuartile Range) for age and tumor size, and n (\%) for categorical variables were used. Mann Whitney U test was used to compare p53 and Ki67 staining scores according to age, tumor diameter, sex, and tumor location. Relationships between marker staining rates according to age, tumor diameter, sex, and sample location were investigated by Spearman rank correlation coefficient $(\rho)$. Sample locations according to sex were compared with Chi-Square test. ChiSquare (Likelihood ratio) test was used to compare Ki67 proliferation index according to tumor location and sex.

The Kruskal-Wallis nonparametric variance analysis was used to compare tumor size according to p53 marker staining score. The Mann Whitney $\mathrm{U}$ test was used to compare tumor diameters according to the Ki67 marker staining score, since Ki67 marker was a single high intensity score.

The MS-Excel 2010 and IBM SPSS Statistics 22.0 (IBM Corp. Release 2013. IBM SPSS Statistics for Windows, Version 22.0, Armonk, NY, USA) programs were used for statistical analysis and calculations. Statistical significance was accepted as $\mathrm{p}<0.05$.

\section{RESULTS}

The total number of BCC cases who were sent to our clinic between 2006 and 2017 was 1208.622 (51.6\%) of the cases were male and $586(48.6 \%)$ of the cases were female. The mean age of the cases was 65.19 years (min 16- max 94 years).

In this study, nineteen of the total 33 cases (57.6\%) were female, $14(42.4 \%)$ were male. Twenty-one (63.6\%) of the samples were in the usual location and $12(36.4 \%)$ were in unusual locations. These unusual locations were 2 cases involving the vulva, 2 in the inguinal region, 2 in the umbilicus and one each in the acral (periungal), anal, nipple-areola complex, sacral and axilla regions. The usual location rate of samples taken from female patients was $63.2 \%(n=12)$ and the rate of tumors that have usual locations from male patients was $64.3 \%(n=9)$. The usual location of the samples taken from male and female patients was similar $\left(x^{2}=0.004 ; p=0.947\right)$. The median age of the patients with a sample from a usual and an unusual location was statistically insignificant $(\mathrm{Z}=1.124, \mathrm{p}=0.274)$.

The diameters of the tumors ranged from 0.3 to $8.0 \mathrm{~mm}$, while the median was $0.8(\mathrm{IQR}=1.1) \mathrm{mm}$. There was only a weak correlation between patient age and tumor diameters in the linear direction $(r=0.365, p=0.037)$. According to sex, there was no significant correlation between age and tumor diameter in male patients $(\mathrm{r}=0.280 ; \mathrm{p}=0333)$ and there was 
a strong correlation between age and tumor diameter in female patients $(\mathrm{r}=0.567 ; \mathrm{p}=0.011)$. Tumor diameters in the samples taken from male and female patients were similar $(p=0.602)$. Tumors which arise from unusual locations were larger than the ones that have usual locations. This result was statistically significant ( $\mathrm{p}=0.001$ ) (Table I).

Tumor cells were stained with p53 at a rate of at least 1.0\% and at most $90.0 \%$. The staining median for p53 was $20 \%$ $(\mathrm{IQR}=30.0 \%)$. With Ki67, these values were determined as $3.0 \%-75.0 \%$ respectively and the median was $10.0 \%$ (10.0\%). The staining rates of both markers did not differ according to the location of the specimen ( $p>0.05$ ) (Table II).

There was a linear correlation between the Ki67 and p53 marker staining rates but it was only moderate $(\rho=0.420$; $\mathrm{p}=0.015)$. In the samples taken from female patients, there was a linear and moderate relationship between the markers $(\rho=0.501 ; p=0.029)$, but no significant relationship was observed between the markers in the male patients ( $\rho=0.269 ; p=0.353$ ). In the samples taken from the usual region, there was a linear and moderate relationship between the markers $(\rho=0.513 ; p=0.017)$, whereas there was no significant relationship between the markers in the samples taken from the unusual region $(\rho=0.504 ; p=0.095)$.

When the p53 and Ki67 staining rates were re-scored as " 0 , low and high", 22 (66.6\%) of the p53 staining scores was 'low' and 5 (15.2\%) were 'high' (Figure 2) while 6 were (18.2\%) ' 0 '. 19 (57.6\%) of the Ki67 staining scores were 'low' (Figure 3), 1 (3.0\%) was 'high' and 13 (39.4\%) were '0'. The Ki67 staining score was found to be independent of the sample location $\left(\chi^{2}=2.240 ; p=0.326\right)$. For the other marker,

Table I: Tumor sizes according to gender and specimen location

\begin{tabular}{|c|c|c|c|c|}
\hline & \multicolumn{2}{|c|}{ Tumor Size (mm) } & \multicolumn{2}{|c|}{ Test Statistics } \\
\hline & Min-Max & Median (IQR) & $\mathrm{Z}$ & p \\
\hline \multicolumn{5}{|l|}{ Gender } \\
\hline Male & $0.3-8.0$ & $1.0(1.4)$ & \multirow{2}{*}{0.531} & \multirow{2}{*}{0.602} \\
\hline Female & $0.4-4.0$ & $0.7(0.5)$ & & \\
\hline \multicolumn{5}{|c|}{ Sample Localization } \\
\hline Usual & $0.3-2.0$ & $0.6(1.7)$ & \multirow{2}{*}{3.162} & \multirow{2}{*}{0.001} \\
\hline Unusual & $0.5-8.0$ & $2.2(2.7)$ & & \\
\hline
\end{tabular}

Table II: p53 and Ki67 marker staining percentages according to sample location

\begin{tabular}{|c|c|c|c|c|}
\hline \multirow{2}{*}{ Markers } & \multicolumn{2}{|c|}{ Percentage $(\%)$} & \multicolumn{2}{|c|}{ Test Statistics } \\
\hline & Min-Max & Median (IQR) & $\mathrm{Z}$ & $\mathbf{p}$ \\
\hline \multicolumn{5}{|l|}{ p53 } \\
\hline Usual & $1.0-90.0$ & $20.0(45.0)$ & \multirow{2}{*}{1.375} & \multirow{2}{*}{0.174} \\
\hline Unusual & $10.0-75.0$ & $22.5(16.3)$ & & \\
\hline \multicolumn{5}{|l|}{ Ki67 } \\
\hline Usual & $3.0-40.0$ & $10.0(10.0)$ & \multirow{2}{*}{0.871} & \multirow{2}{*}{0.397} \\
\hline Unusual & $3.0-75.0$ & $10.0(16.5)$ & & \\
\hline
\end{tabular}

Table III: p53 and Ki67 marker staining scores according to sample location

\begin{tabular}{|c|c|c|c|c|}
\hline \multirow{2}{*}{ Markers } & $\mathbf{0}$ & Low & High & \multirow{2}{*}{ Test Statistics } \\
\hline & n (\%) & n (\%) & n (\%) & \\
\hline \multicolumn{5}{|l|}{ p53 } \\
\hline Usual & $6(28.6)$ & $11(52.4)$ & $4(19.0)$ & \multirow{2}{*}{$\mathrm{N} / \mathrm{A}^{\star}$} \\
\hline Unusual & $0(0.0)$ & $11(91.7)$ & $1(8.3)$ & \\
\hline \multicolumn{5}{|l|}{ Ki67 } \\
\hline Usual & $8(38.1)$ & $13(61.9)$ & $0(0.0)^{* *}$ & \multirow{2}{*}{$c^{2}=2.240 ; p=0.326$} \\
\hline Unusual & $5(41.7)$ & $6(50.0)$ & $1(8.3)$ & \\
\hline
\end{tabular}

${ }^{*}$ N/A : Not Applicable, ${ }^{* *}$ no case 


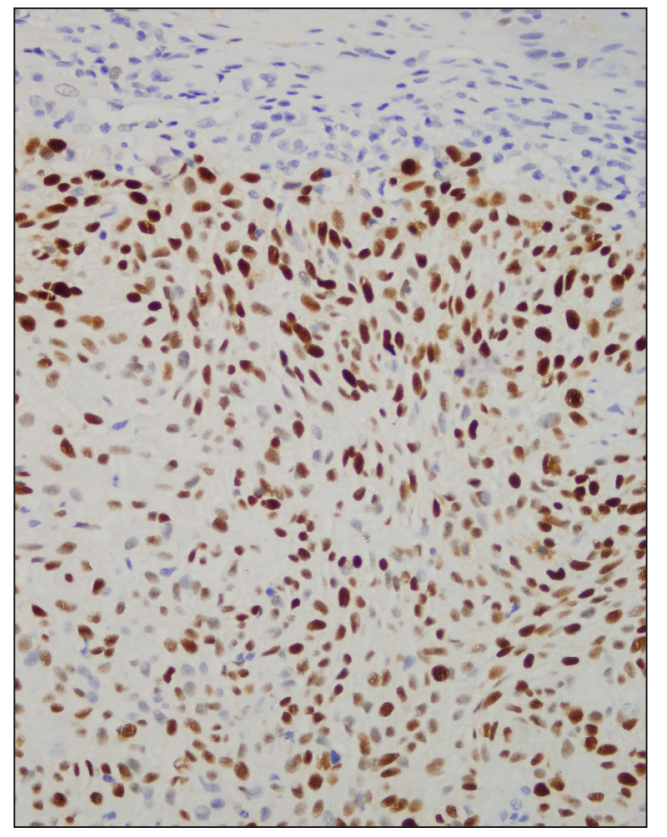

Figure 2: Immunohistochemical p53 high score expression of a BCC case in the head and neck region (IHC; x400).

p53, the staining score classification was not comparable according to the sample location (Table III).

Gender and p53 staining score were not compared. Ki67 staining score was found to be independent of sex, and there was no difference in staining score according to sex $\left(c^{2}=1.337 ; \mathrm{p}=0.502\right)$.

When the tumor diameter was compared according to the p53 and Ki67 staining scores, the median tumor diameter was $0.9(\mathrm{IQR}=1.8) \mathrm{mm}$ in the high staining score cases while the median tumor diameter was $1.0(\mathrm{IQR}=1.7) \mathrm{mm}$ in the low staining score cases for p53. Tumor diameter median was similar to the markers' staining score $(\mathrm{p}>0.05)$.

\section{DISCUSSION}

BCC cases are most commonly seen in sun-exposed areas (1-13). Cases in the vulva, inguinal region, axilla, nippleareola complex, umbilical, periungal, scrotal and anal regions are accepted to be unrelated to sunlight (8).

A previous study reported that the rate of BCC cases in an unusual location was $1.12 \%$ among all cases (14). We found similar results in our study with BCC cases that were consulted to our clinic between 2006 and 2016 (15). The rate was found to be $0.99 \%$. in our study

The risk of developing BCC increases over 60 years(16). Metastatic tumors are also usually larger in size. In our study, the tumor size increased as the age increased. This result was statistically significant $(\mathrm{p}=0.037)$.

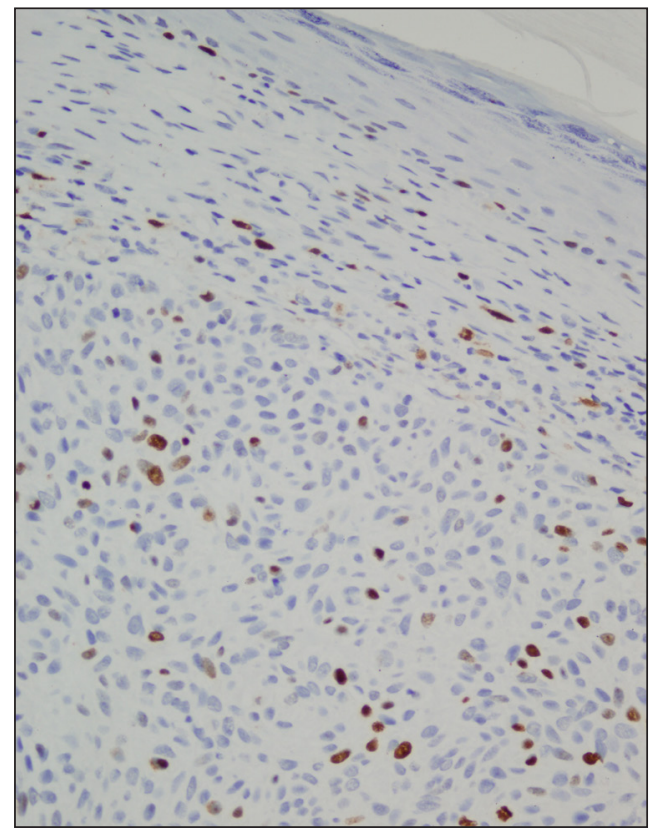

Figure 3: Ki67 staining had a low score in a BCC case in the anal region (IHC; $\mathrm{x} 400$ ).

Between 1 and $10 \%$ of UV light reaches earth as UV-B and $90 \%$ of it as UV-A. UV-B light causes p53 mutation because of genotoxicity and absorption by keratinocytes. Wild-type (wt) p53 protects the genome and it ends the cell cycle during the G1 phase after DNA damage. Wt p53 is increased after DNA damage. Increase of p53 in the epidermis after sunlight damage causes an arrest of the cell cycle or recovery of the damage. Mutant p53 is more stable than wt p53 and it accumulates in the cell (9).

Immunohistochemical p53 expression is accepted as an indirect marker of mutation. It is thought that P53 mutation occurs in the earlier period of cutaneous neoplasms. Additionally, p53 mutation is also seen in actinic keratoses and normal cutaneous epidermis $(6,9)$.

Previous studies have found p53 expression in cutaneous neoplasms to vary between $42 \%$ and $84 \%(17,18)$. In our study, the expression was found to be $81.8 \%$. The reason for this variability seems to be the different staining techniques and different evaluation systems for p53 immunoreactivity.

Previous studies did not find any difference related to p53 expression levels among aggressive and non-aggressive BCC variants. De Rosa et al. compared p53 expression levels between aggressive and non-aggressive $\mathrm{BCC}$ variants. p53 expression levels among aggressive BCC cases were discovered to be higher (19). We could not evaluate the relation between BCC types and p53 expression because of our limited case number. In fact, p53 expression levels of subtypes should be evaluated with larger study groups. 
It is emphasized that masses that metastasize in BCC are generally larger in size $(16,21)$. It has been reported that p53 expression is common in malignant epithelial lesions, but not in association with malignant phenotype or metastasis (20). We also found no correlation between tumor size and $\mathrm{p} 53$ expression $(\mathrm{p}=0.235)$.

P53 gene mutation is significant in skin tumors following UV light exposure. The p53 staining score would be expected to be different between cases in an unusual location that were not exposed to the sun compared to those from in a usual location with exposure to the sun but there was no difference in some studies $(17,19,21)$. Ansarin et al. reported no correlation regarding the 553 immunoreactivity pattern and the site of the lesion.

Ki67 is associated with condensed chromatin surface and chromosomes. It is localized in the nucleocytoplasm before its nucleus location after cell division. Ki67 is expressed as late G1-M and G2-M phase (9). Ki67 proliferation index among BCC cases was found to be between $1 \%$ and $61 \%$ in previous studies (22). In our study, Ki67 expression was seen in all cases. The Ki67 proliferation indexes of our cases were determined to be between $3 \%$ and $75 \%$. No correlation between tumor size and Ki67 expression levels was found in the literature (22). Moreover, we did not find any correlation between tumor size and Ki67 expression levels and this was compatible with the literature $(\mathrm{p}=0.500)$.

In our study, a correlation was found between Ki67 and p53 expression percentage levels $(\mathrm{p}=0.015)$. This is an expected result which determines that Ki67 is a marker showing proliferation and p53 is related with an aggressive progress $(19,22)$. Furthermore, in our study, there was a linear and moderate correlation ( $\mathrm{p}=0.029)$ between the markers in the samples taken from the female patients, but no significant correlation was observed between the markers in the male patients $(\mathrm{p}=0.353)$. In the samples taken from the usual region, there was a linear and moderate relationship $(p=0.017)$ between the markers, whereas there was no significant relationship between the markers in the samples taken from the unusual region $(\mathrm{p}=0.095)$. The correlation between both markers in both women and the usual areas may be due to increased sun exposure with the use of a tanning bed for women.

The patient number enrolled in our study group with BCC in an unusual location was quite limited. In our study, p53 antibody staining, which was positive in all BCC cases in an unusual location, was studied immunohistochemically. In fact it should be studied with an increased number of cases and further genetic techniques.
In conclusion, this is the first study comparing the expression profiles of p53 and Ki67 in BCC cases in an unusual location and BCC cases in an usual location. No significant difference was found concerning Ki67 and p53 expression levels between the two groups. This result demonstrates that several factors such as advanced age, trauma, arsenic intake, male gender and immunosuppression also had effects on p53 damage besides exposure to sunlight.

Indeed, further studies with larger groups are necessary to research p53 and Ki67 expression levels in more aggressively progressing BCC cases and those in an unusual location.

\section{CONFLICT of INTEREST}

The authors declare no conflict of interest.

\section{REFERENCES}

1. Jacob A. Observations respecting an ulcer of peculiar character, which attacks the eyelids and other parts of the face. Dublin Hospital Rep Commun Med Surg. 1827;4:232-9.

2. Pisani C, Poggiali S, Padova LD, Andreassi A, Bilenchi R. Basal cell carcinoma of the vulva. JEADV. 2006;20:446-8.

3. Telfer NR, Colver Gb, Morton CA. Guidelines for management of basal cell carcinoma. Br J Dermatol. 2008;159:35-48.

4. Borgohain M, Manta A. Basal cell carcinoma of the perianal region- a diagnostic dilemma. Indian Journal of Medical Case Reports. 2015;4:23-5.

5. Ghaderi R, Haghighi F. Immunohistochemistry Assessment of p53 protein in basal cell carcinoma. Iran J Allergy Asthma Immunol. 2005;4:167-71.

6. Karagece Yalçin U, Seçkın S. The Expression of p53 and Cox-2 in Basal cell carcinoma, squamous cell carcinoma and Actinic Ceratosis cases. Turk Patoloji Derg. 2012;28:119-27.

7. Khodaeiani E1, Fakhrjou A, Amirnia M, Babaei-Nezhad S, Taghvamanesh F, Razzagh-Karimi E, Alikhah H. Immunohistochemical evaluation of p53 and Ki67 expression in skin epithelial tumors. Indian J Dermatol. 2013;58:181-7.

8. Abeldaño A, Hernández MI, Demarchi M, Cedeño LP, Brea P, Kien C, Chouela E, Pellerano G. Basal cell carcinoma of unusual localization. Dermatol Argent. 2010;16:25-33.

9. Mateoiu C, Pirici A, Bogdan F. Immunohistochemical nuclear staining for p53, PCNA, Ki67 and bcl-2 in different histologic variants of basal cell carcinoma. Rom J Morphol Embryol. 2011;52:315-9.

10. Dourmishev LA, Rusinova D, Botev I. Clinical variants, stages and management of basal cell carcinoma. Indian Dermatol Online J. 2013;4:12-7.

11. Vantuchova Y, Curik R. Histological types of basal cell carcinoma. Scripta Medica (BRNO). 2006;79:261-70.

12. Bulus H, Akyürek Ö, Akbal E, Yavuz A, Aydın A, Şimşek G. Perianal basal cell carcinoma: An uncommon localization. Turk J Gastroenterol. 2014;25 Suppl 1:239-40.

13. Margo CE, Waltz K. Basal cell carcinoma of eyelid and periocular skin. Surv Ophthalmol. 1993;38:169-92. 
14. Dagatti MS, Cesarios G, Feijóo F, Martínez M. Epiteliomas basocelulares de localización infrecuente. Arch Argent Dermatol. 2006;56:55-8.

15. Sungu N, Kiran M, Dogan HT, Kilıcarslan A, Karakok E et al. Unusual localized Basal Cell carcinomas: Retrospective study and review of literature. Turk J Dermatol. 2017;11:109-13.

16. LeBoit PE, Burg G, Weedon D, Sarasin A. Pathology and genetic skin tumours. Lyon:IARC, 2006.

17. Merct R, Ciurea ME, Margarıtescu C,Popescu SM, Crăitoiu MM, Cotoi OS, Voinescu DC. Expression of p53, D2-40 and alphasmooth muscle actin in different histological subtypes of basal cell carcinoma. Rom J Embryol. 2014;55: 263-72.

18. Koseoglu RD, Sezer E, Eyibilen A, Aladag I, Etikan I. Expressions of p53, cyclin D1 and histopathological features in basal cell carcinomas. J Cutan Pathol. 2009;36:958-65.
19. De Rosa G, Staibano S, Barra E, Donofrio V, Salvatore G, Vessecchia G, Boscaino A. p53 protein in aggressive and nonaggressive basal cell carcinoma. J Cutan Pathol. 1993;20:429-34.

20. Demirkan NC1, Colakoglu N, Düzcan E. Value of p53 protein in biological behavior of basal cell carcinoma and in normal epithelia adjacent to carcinomas. Pathol Oncol Res. 2000;6:272-4.

21. Ansarin H, Daliri M, Soltani-Arabshahi R. Expression of p53 in aggressive and non-aggressive histologic variants of basal cell carcinoma. Eur J Dermatol. 2006;16:543-7.

22. Kramer E, Herman O, Frand J, Leibou L, Schreiber L, Vaknine H. Ki67 as a biologic marker of Basal Cell carcinoma: A retrospective study. Isr Med Assoc J. 2014;16:229-32. 